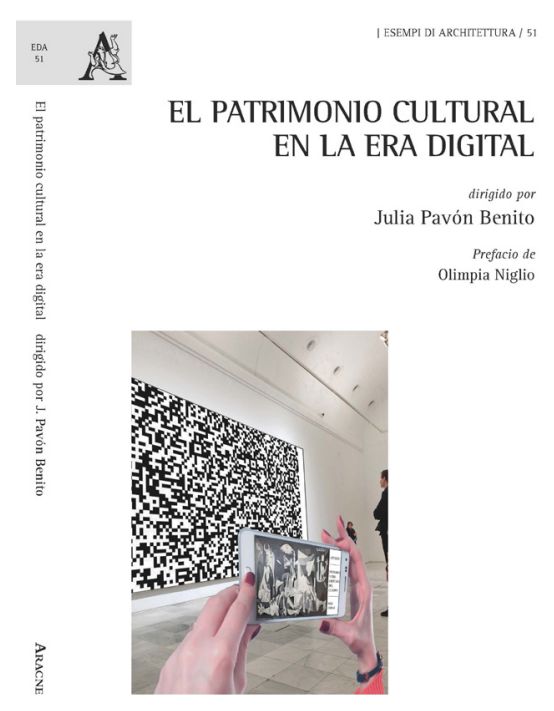

Pavón Benito, J. (dir.)

\section{El patrimonio cultural en la era digital}

Canterano: Aracne editrice, 2020

Como puede deducirse del título, El patrimonio cultural en la era digital, estamos ante una obra que en sí misma supone un desafío en materia de cultura, divulgación y museos. Un mundo cada vez más cambiante e hiperconectado exige un esfuerzo mayor a la hora de entender la realidad en la que vivimos, especialmente cuando ciertos canales comunicativos y lenguajes terminan por confluir.

Si aplicamos este planteamiento al mundo de los museos, observamos cómo la adopción de las nuevas tecnologías de la información ha hecho posible extender sus contenidos más allá de la materialidad de la institución en su sentido más tradicional. Sin embargo, esa irrupción de lo virtual en lo cotidiano merece un análisis sosegado, ya que disponibilidad o inmediatez no son, necesariamente, sinónimos de excelencia. Asumir que cualquier proyecto es válido por el mero hecho de ser creativo en forma, de poseer lo que podríamos llamar una identidad digital, supone incurrir en el grave error de descuidar los pormenores de los procesos cognitivos, o peor aún, de reducirlos a una visión utilitarista de las cosas.

En el libro se desarrollan media docena de contribuciones en las que se reúnen, valoran y sopesan distintas propuestas, todas ellas surcadas por el denominador común de la digitalización.

El primer trabajo, "Introducción. El laberinto del patrimonio cultural en la era digital", propone un recorrido en torno a la noción de museo desde el coleccionismo primigenio a nuestro tiempo. Indaga en la razón primaria por la cual existen estos espacios, introduciendo elementos esenciales que los fundamentan y legitiman, como lo son la memoria o la curiosidad. Al mismo tiempo, apuesta por estimular el aprendizaje continuo, aplicando toda esa experiencia previa al Museo de Navarra.

La segunda aportación, "El Museo en la web: los museos en la era de la reproductibilidad digital", realiza un repaso sobre la trayectoria divulgativa de los contenidos de la web del Museo del Prado como proyecto de ilustración digital a gran escala, accesible, sensorial y en constante crecimiento.

En una línea similar, y sin abandonar el rico debate en torno a la transformación digital, se desarrolla el siguiente trabajo: "Museo Reina Sofía: procesos y funciones en la era digital". En él se muestra la labor desarrollada por el departamento digital de la institución en su web, así como los ejes de 
actuación más importantes: el trabajo multimedia, la promoción de la radio digital o el galardonado Repensar el Guernica, un verdadero desafío a nivel artístico-documental.

Por su parte, "Centro Botín: artes, emociones y creatividad", pretende reivindicar un discurso en el que se premia la creatividad mediante propuestas artísticas propias que apelan a lo emocional. Este estímulo también está presente en el siguiente texto, "Museo Virtual de Sefarad", en el que se rompe una lanza en favor del legado judaico en la Península Ibérica, al tiempo que se analizan los parámetros que permiten calibrar y evaluar la viabilidad del proyecto (diseño y objetivos, accesibilidad, visibilidad, flexibilidad, costes...); ingredientes que, en suma, permiten avanzar en la definición de una misión, visión y valores propios.

El último estudio, "Del museo a la iglesia. La digitalización y reproducción del patrimonio sacro medieval del Valle de Arán", recoge el espíritu de los proyectos anteriores, impulsándose en la digitalización y mecanizado del material escultórico en este espacio mediante la aplicación de la tecnología 3D.

En resumen, estamos ante un trabajo sencillo en forma, pero extremadamente maduro en la exposición de sus contenidos. Una contribución que, como afirmábamos al comienzo, supone un desafío, pero también una oportunidad de conciliar pasado, presente y futuro.

\section{Ana Isabel Castro Carbonell | Gestora cultural}

URL de la contribución <www.iaph.es/revistaph/index.php/revistaph/article/view/4974> 